\title{
Immune Cell Infiltrates in Atypical Teratoid/Rhabdoid Tumors
}

\author{
Jian-Qiang Lu, Beverly A. Wilson, V. Wee Yong, Jeffrey Pugh, Vivek Mehta
}

\begin{abstract}
Objective: Atypical teratoid/rhabdoid tumor (AT/RT) is a highly malignant tumor of the central nervous system. Its pathogenesis remains unknown. Like glioblastomas, AT/RTs contain brain cancer stem cells (CSCs) that suppress the immunity of patients and are resistant to conventional chemotherapy and radiation therapy. Considerable infiltration of immune cells, including macrophages/microglia, dendritic cells and T-cells, has been noted in glioblastomas, which correlates with poor prognosis. The present study examines the significance of infiltrating immune cells in four cases of AT/RT; including one associated with an autoimmune disease, Henoch-Schonlein purpura. Methods: Tumor tissues from four patients with AT/RT were analyzed and compared with those from four patients with glioblastomas. The frequency of immune cells, including CD68+, CD4+, and CD8+ cells, was assessed by scoring for statistical analysis. Results: The infiltration of immune cells was identified in the case of AT/RT associated with HSP and three other cases of infratentorial AT/RTs. Moderate infiltration of CD68+ macrophages/microglia and CD4+ cells was noted in AT/RTs with no significant difference from that in glioblastomas $(p>0.05)$. However, the infiltration of CD8+ T-cells was significantly higher in AT/RTs than that in glioblastomas $(p<0.05)$; CD4+/CD8+ ratio was significantly lower in AT/RTs than that in glioblastomas $(p<$ 0.05). In addition, eosinophils were found in all AT/RTs, but not in glioblastomas. Conclusions: These findings suggest an immune microenvironment of AT/RTs with more immune effectors than glioblastomas. Our observation contributes to understanding the growth environment of AT/RTs for which adjuvant immunotherapy may be potentially beneficial.
\end{abstract}

RÉSUMÉ: Infiltrat de cellules immunitaires dans les tumeurs teratoïdes/rhabdoïdes atypiques. Objectif : La tumeur tératoïde/rhabdoïde atypique (TT/RA) est une tumeur très maligne du système nerveux central. Sa pathogenèse demeure inconnue. Comme les glioblastomes, les TT/RA contiennent des cellules souches du cancer du cerveau qui suppriment l'immunité des patients et sont résistantes à la chimiothérapie et à la radiothérapie conventionnelles. Une infiltration considérable par des cellules immunitaires dont des macrophages/microglie, des cellules dendritiques et des cellules T a été observée dans les glioblastomes, entraînant un mauvais pronostic. Cette étude examine la signification des cellules immunitaires chez quatre cas de TT/RA dont un était associé à une maladie autoimmune, le purpura de Henoch-Schonlein (PHS). Méthode : Du tissu tumoral provenant de 4 patients atteints d'une TT/RA a été analysé et comparé à du tissu provenant de 4 patients atteints de glioblastomes. Le nombre de cellules immunitaires dont des cellules CD68+, CD4+ et CD8+ a été évalué. Résultats : L'infiltration par des cellules immunitaires a été identifiée chez le cas de TT/RA associé au PHS et chez 3 autres cas de TT/RA sous-tentoriels. Une infiltration modérée par des macrophages/microglie CD68+ et des cellules CD4+ a été observée dans les TT/RA sans qu'on note de différence significative par rapport aux glioblastomes $(\mathrm{p}>0,05)$. Cependant, l'infiltration par des cellules T CD8+ était significativement plus importante dans les TT/RA que dans les glioblastomes $(p<0,05)$; le ratio CD4+/CD8+ était significativement plus bas dans les TT/RA que dans les glioblastomes $(\mathrm{p}<0,05)$. De plus, des éosinophiles étaient présents dans toutes les TT/RA, mais absents dans les glioblastomes. Conclusions : Ces observations sont en faveur d'un microenvironnement immunitaire dans les TT/RA étant donné la présence de plus de cellules effectrices que dans les glioblastomes. Nos observations contribuent à la compréhension de l'environnement dans lequel se développent les TT/RA pour lesquels une immunothérapie adjuvante pourrait peut-être être bénéfique.

Can J Neurol Sci. 2012; 39: 605-612

Atypical teratoid/rhabdoid tumor (AT/RT) is a rare, highly malignant tumor of the central nervous system (CNS) most commonly found in children ${ }^{1}$. Its prognosis is dismal, with a historic median survival ranging from 6 to 11 months ${ }^{2}$. However, recent studies have shown a significant improvement in time to progression and survival for some patients who received surgical resections followed by high-dose chemotherapy and autologous stem cell rescue ${ }^{2-4}$. The pathogenesis of AT/RT is still unclear and it may be instructive to glean findings from malignant gliomas. It has been noted that AT/RT, like malignant gliomas, contains brain cancer stem cells $(\mathrm{CSCs})^{5}$. CSCs play an important role in tumor initiation and are often resistant to conventional chemotherapy and radiation therapy ${ }^{5,6}$. On the other hand, the immunotherapy targeting CSCs have achieved promising results ${ }^{6}$. Cancer stem cells have been shown to suppress adaptive immunity and to modulate innate immunity in glioblastomas by inducing immunosuppressive macrophages/ microglia ${ }^{7}$. Macrophages/microglia constitute the dominant tumor-infiltrating immune cells ${ }^{8}$. Instead of phagocytizing tumor cells or debris, activated microglia or macrophages may promote

From the Department of Laboratory Medicine and Pathology (JQL), Department of Pediatrics (BAW), Department of Surgery (JP, VM), University of Alberta, Edmonton; Department of Oncology and Clinical Neurosciences (VWY), University of Calgary,

Calgary, Alberta, Canada.

Received February 3, 2012. Final Revisions Submitted April 2, 2012. Correspondence to: Jian-Qiang Lu, Neuropathology Section, Department of Laboratory Medicine \& Pathology, 5B2.24 WCM Health Sciences Centre, University of Alberta, 8440-112 Street, Edmonton, Alberta T6G 2B7, Canada.

Email: jian-qiang.lu@ualberta.ca. 
tumor growth by facilitating immunosuppression of the tumor microenvironment ${ }^{9}$. The presence of macrophages correlates with poor prognosis in a variety of malignancies ${ }^{10}$. Other infiltrating immune cells identified in glioblastomas include myeloid dendritic cells, plasmacytoid dendritic cells, natural killer (NK) cells and T-cells ${ }^{11,12}$. T-cells specifically of the CD4+ subset have depressed function in the presence of glioblastomas, so do B-cells ${ }^{13}$. The infiltration of CD8+ cytotoxic T-cells may be more perivascular than intratumoral in glioblastomas ${ }^{12}$. Glioblastomas have also a lower CD4+/CD8+ ratio ${ }^{11}$. The degree of lymphocyte infiltration into gliomas has been found to correlate with patient survival ${ }^{12,14,15}$. The conventional treatment of glioblastomas, with concomitant temozolomide and radiation therapy, has shown immune modulation effects with a decrease in total CD4+ cells and effector CD8+ T-cells, which may contribute to some encouraging outcomes of this treatment ${ }^{16}$.

We have recently identified a case of AT/RT (Case 1 in the present study, the Table) that was found incidentally during the work-up for intracranial involvement of Henoch-Schonlein purpura (HSP). Henoch-Schonlein purpura is an immunemediated vasculitis, with some evidence of genetic susceptibility ${ }^{17-19}$. This association of AT/RT with HSP raises the question of whether the immune cell infiltrates might be more significant and influential to the progression of AT/RTs. The present study examines the significance of infiltrating immune cells in AT/RTs, compared to that in glioblastomas which are considered immunogenic tumors ${ }^{20,21}$ and where immune mechanisms and therapy have been extensively studied ${ }^{6-9}$.

\section{Materials And Methods \\ Patients and study design}

Four patients with AT/RTs diagnosed between 2004 and 2010 are included in this study. Four consecutive patients with standard glioblastomas (excluding the variants, such as giant cell glioblastomas, gliosarcomas, and small cell glioblastomas) diagnosed between October 2010 and March 2011 are employed for comparison. Patient characteristics are shown in the Table. All the patients received their surgical procedures at the University of Alberta Hospital. Prior to the surgeries, the patients received only Decadron; no chemotherapy or radiation therapy was administered. Neither their clinical presentation nor preoperative workup suggested a primary infectious/ inflammatory disease or another concurrent disease in these patients, except for one patient (Case 1, described below). The surgical specimens were sent to the Department of Pathology for pathological examination. The diagnosis of brain AT/RTs and glioblastomas was confirmed by two neuropathologists. The tumors are classified according to international guidelines as published in the 2007 World Health Organization (WHO) Classification of Tumors of the Central Nervous System ${ }^{22}$. This study was approved by our institutional Committee on Human Research.

\section{Report of one AT/RT case}

Case 1 (in the Table) was a 34-month-old girl who presented with abdominal pain accompanied by intermittent vomiting and bloody diarrhea for one month before the surgical resection of

\section{Table: Patient clinical and pathological features}

\begin{tabular}{|c|c|c|c|c|c|c|c|c|}
\hline \multirow[b]{2}{*}{ Case } & \multirow[b]{2}{*}{ Age, Sex } & \multirow[b]{2}{*}{ Clinical presentation } & \multirow[b]{2}{*}{ MRI } & \multirow[b]{2}{*}{ Diagnosis } & \multicolumn{4}{|c|}{ Scores* } \\
\hline & & & & & CD68+cells & CD4+cells & CD8+cells & CD4+/CD8+ \\
\hline 1 & $34 \mathrm{mo}, \mathrm{F}$ & $\begin{array}{l}\text { History of HSP (see Text), irritability, } \\
\text { ataxia, nausea/vomiting }\end{array}$ & $\begin{array}{l}\text { Mass }(\sim 5.0 \mathrm{~cm}) \text { with heterogeneous } \\
\text { enhancement in the posterior fossa }\end{array}$ & $\mathrm{AT} / \mathrm{RT}$ & 19.00 & 22.00 & 17.33 & 1.27 \\
\hline 2 & $13 \mathrm{mo}, \mathrm{M}$ & $\begin{array}{l}\text { Irritability, nausea/vomiting, worsening } \\
\text { motor function for } 2 \text { mo }\end{array}$ & $\begin{array}{l}\text { Mass }(\sim 5.2 \mathrm{~cm}) \text { with heterogeneous } \\
\text { enhancement in the } 4 \text { th ventricle }\end{array}$ & $\mathrm{AT} / \mathrm{RT}$ & 21.33 & 23.67 & 16.00 & 1.48 \\
\hline 3 & $17 \mathrm{mo}, \mathrm{M}$ & $\begin{array}{l}\text { Ataxia, nausea/vomiting, left-sided tilt for } \\
2 \text { days }\end{array}$ & $\begin{array}{l}\text { Mass }(\sim 3.5 \mathrm{~cm}) \text { with peripheral } \\
\text { enhancement in the cerebellar vermis }\end{array}$ & $\mathrm{AT} / \mathrm{RT}$ & 11.33 & 18.67 & 6.67 & 2.80 \\
\hline 4 & $6 \mathrm{mo}, \mathrm{M}$ & $\begin{array}{l}\text { Weight loss, progressive lethargy and } \\
\text { irritability }\end{array}$ & $\begin{array}{l}\text { Mass }(\sim 3.7 \mathrm{~cm}) \text { with peripheral } \\
\text { enhancement in the right cerebellum }\end{array}$ & $\mathrm{AT} / \mathrm{RT}$ & 20.67 & 18.33 & 11.67 & 1.57 \\
\hline Median & & & & & $19.83 \ddagger$ & $20.33 \ddagger$ & $13.83 \S$ & $1.53 \S$ \\
\hline 5 & $52 \mathrm{yr}, \mathrm{M}$ & $\begin{array}{l}\text { Weakness of the left hand, followed by } \\
\text { new-onset seizure }\end{array}$ & $\begin{array}{l}\text { Mass }(\sim 3.5 \mathrm{~cm}) \text { with ring enhancement in } \\
\text { the right frontal lobe }\end{array}$ & GM & 17.67 & 22.67 & 3.00 & 7.56 \\
\hline 6 & $72 \mathrm{yr}, \mathrm{F}$ & $\begin{array}{l}\text { History of ischemic stroke, worsening left- } \\
\text { sided weakness }\end{array}$ & $\begin{array}{l}\text { Mass }(\sim 3.5 \mathrm{~cm}) \text { with patchy enhancement } \\
\text { in the right frontal lobe }\end{array}$ & GM & 15.00 & 19.33 & 3.33 & 5.80 \\
\hline 7 & $69 \mathrm{yr}, \mathrm{M}$ & Cognitive decline for weeks & $\begin{array}{l}\text { Mass }(\sim 5.1 \mathrm{~cm}) \text { with heterogeneous } \\
\text { enhancement in the right parietal lobe }\end{array}$ & GM & 8.67 & 21.67 & 2.00 & 10.83 \\
\hline 8 & $60 \mathrm{yr}, \mathrm{M}$ & New-onset seizure, headaches & $\begin{array}{l}\text { Mass }(\sim 5.7 \mathrm{~cm}) \text { with heterogeneous } \\
\text { enhancement in the right temporal lobe }\end{array}$ & GM & 10.33 & 22.67 & 2.67 & 8.50 \\
\hline Median & & & & & 12.67 & 22.17 & 2.83 & 8.03 \\
\hline
\end{tabular}

mo, months; yr, years; M, male; F, female; HSP, Henoch-Schonlein purpura; AT/RT, atypical teratoid/rhabdoid tumors; GM, glioblastomas; $\sim$, up to the maximum dimension. * Values represent the averages of 3 sums of scores; the frequencies of CD68+, CD4+, and CD8+ cells in each high-power ( $\mathrm{x}$ 400) microscopic field are scored from 0 to 3 (see Text) and then the scores of 10 consecutive high-power microscopic fields are summed. $\ddagger \mathrm{p}>0.05$ by Mann-Whitney test vs. glioblastomas. $\S \mathrm{p}<0.05$ by Mann-Whitney test vs. glioblastomas. 
AT/RT. She developed purplish rash on her legs and buttocks with a right swollen knee later in that period. Gait abnormality was also found in the form of poor balance and difficulty in standing. Physical examination 20 days before the surgery revealed palpable purpura over the lower extremities, grossly larger right knee, and inability to weight-bear on both her legs. Her immunizations were up-to-date. She was previously healthy with no prenatal or perinatal complications, but she did have some upper respiratory tract infection symptoms including cough and runny nose before this presentation. Her family history was non-contributory. She was diagnosed with $\mathrm{HSP}^{17,19}$.

Routine laboratory blood tests (not including immunology) showed no consistent abnormality before the surgery. Her ataxia became prominent, although she had no complaints of headache. Pre-operative MRI disclosed a heterogeneously T1-weighted iso-intense and T2-weighted hyper-intense mass $(5.0 \times 4.5 \times 3.9$ $\mathrm{cm})$ with heterogeneous enhancement after the administration of gadolinium (Figure 1). She underwent surgical resection of the mass. Histopathological and immunohistochemical studies of the tumor specimen resulted in the diagnosis of AT/RT ${ }^{22}$.

After the surgical resection, the patient received two courses of high-dose chemotherapy (including carboplatin, and thiotepa) and stem cell rescue within nine months, along with posterior fossa radiation for a total dose of $5400 \mathrm{cGy}$, over seven weeks. Followup MRIs revealed no evidence of tumor recurrence for at least 12 months after the surgical resection.

\section{Histopathology and immunohistochemistry}

The surgical specimens were formalin-fixed, routinely processed, paraffin-embedded, sectioned at $5 \mu \mathrm{m}$, and stained with hematoxyline and eosin $(\mathrm{H} \& \mathrm{E})$ and immunohistochemical methods. The H\&E slides were examined for morphological features. Immunohistochemistry was performed on tissue sections using the EnVision ${ }^{\mathrm{TM}}$ FLEX Mini Kit, High $\mathrm{pH}$ (Autostainer/Autostainer Plus; Dako, Carpinteria, CA, USA) detection system after the tissue was deparaffinised and rehydrated according to the standard protocol. The following antibodies were used: CD4 (4B12, Vector), CD8 (C8/144B, Dako), CD68K (KP1, Dako), CD20 (L26, Ventana), CD45 (HCHL1, Dako), CD138 (CD138, Dako), CAM5.2 (CAM5.2, Dako), glial fibrillary acidic protein (GFAP; 6F2, Dako), synaptophysin (polyclonal, Dako), smooth muscle actin (SMA; 1A4, Dako), MIB-1 (MIB-1, Dako), and INI-1 (MRQ-27, Cell Marque).

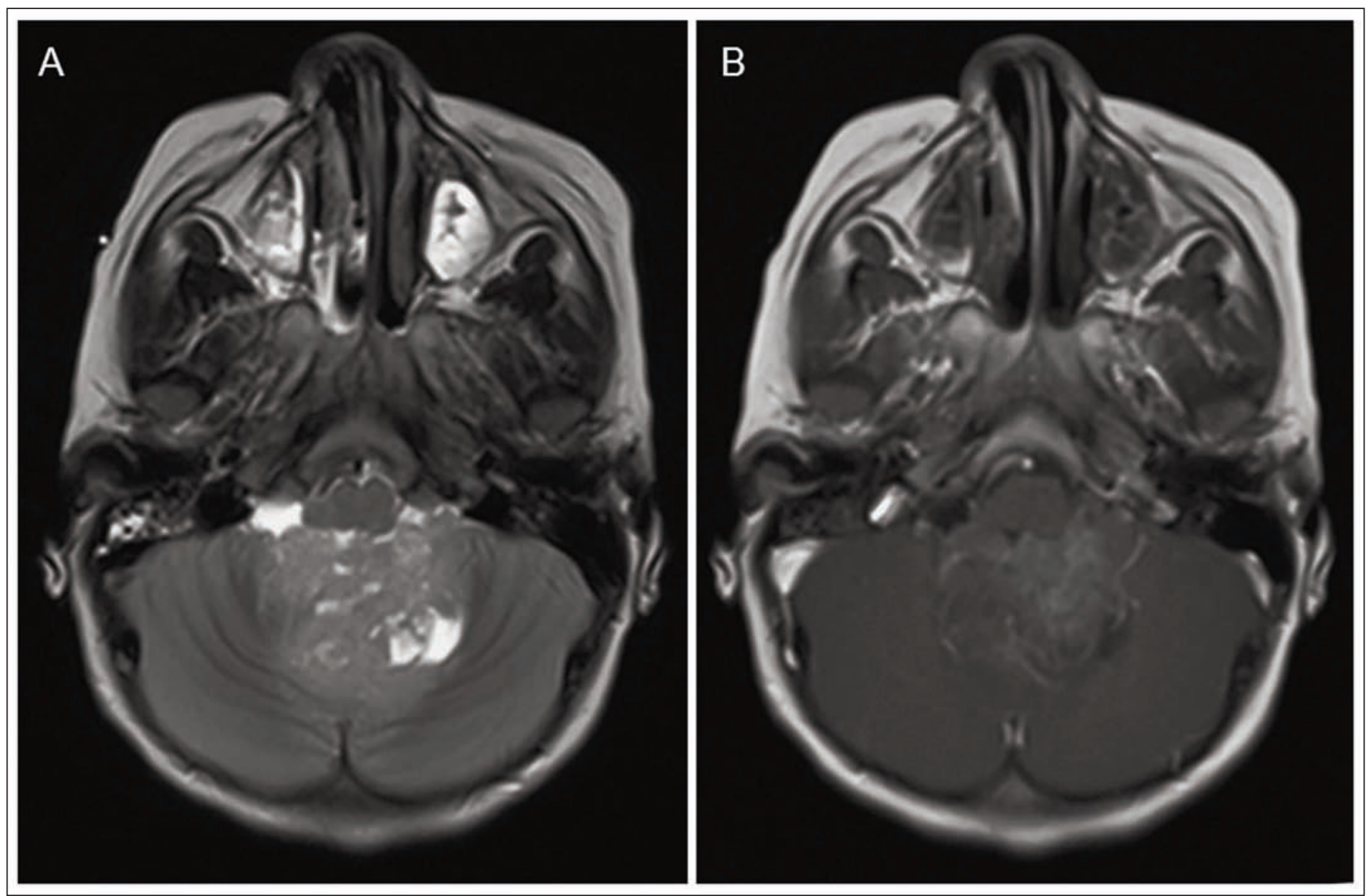

Figure 1: MR imaging of an atypical teratoid/rhabdoid tumor (Case 1, in the Table). Axial (A) T2-weighted and (B) post-gadolinium T1-weighted images show a heterogeneously enhancing mass in the posterior fossa. 
The morphological and immunohistochemical features of each case/slide were reviewed and assessed. The frequency of CD68+ macrophages/microglia, CD4+ cells, CD8+ T-cells was then assessed semi-quantitatively by scoring the percentage of immunoreactive cells per high-power microscopic field (original magnification x 400; $0.16 \mathrm{~mm}^{2}$ ): 0 (for $0 \%$ ), 1 (for $1 \sim 4 \%$ ), 2 (for $5-16 \%$ ), and 3 (for $>16 \%$ ). Scoring was performed preferentially in the areas with the characteristic features of AT/RT or glioblastoma, and most of the microscopic slides have slightly more than 30 high-power microscopic fields that were available for assessment. Immunoreactive cells were defined as those with strong and diffuse immunoreactivity within the cytoplasm. Necrotic or non-tumor areas were excluded in this assessment. The scores of ten consecutive high-power microscopic fields were then summed. The values in the Table represent the averages of three sums of the scores.

\section{Statistical analysis}

The Mann-Whitney test was used to assess the difference in scores between groups. Two-tailed values of $p<0.05$ were regarded as significant.

\section{RESULTS}

\section{Atypical teratoid/rhabdoid tumors (AT/RT)}

The Table summarizes the clinical and radiological features of the four cases of AT/RT. All the patients were under the age of 34 months at time of surgical resections, and their tumors were located in the posterior fossa. As described above, AT/RT in Case 1 was found after HSP was diagnosed. The three other cases had no remarkable history or associated disorders. Pathological examination revealed typical morphological and immunohistochemical features of AT/RTs (Figure 2, Figure 3, and Figure 4A-D). The tumors contained a mixed population of cells comprising variable numbers of rhabdoid cells (Figure 2A), primitive-appearing small cells (Figure 2A-C), focal epithelial (Figure 2B) and mesenchymal (Figure 2C) features. Immunohistochemistry confirmed the AT/RTs exhibited a broad spectrum of reactivity, including focal positivity for GFAP and synaptophysin, as well as patchy positivity for cytokeratin CAM5.2 (Figure 2D) and smooth muscle actin (Figure 2E). The MIB-1 labelling index of proliferation was moderately high. All four cases showed loss of the immunoreactivity for INI-1 in tumor cells, with preservation of the immunoreactivity in the blood vessel cells (Figure 2F).

\section{Glioblastomas}

The four cases of glioblastomas are also summarized in the Table. The patients ranged in age from 52 years to 72 years, and their tumors were supratentorial in location. All the tumors showed the typical histopathological features of standard glioblastomas (Figure 4E) with no convincing features to warrant the diagnosis of a glioblastoma variant.

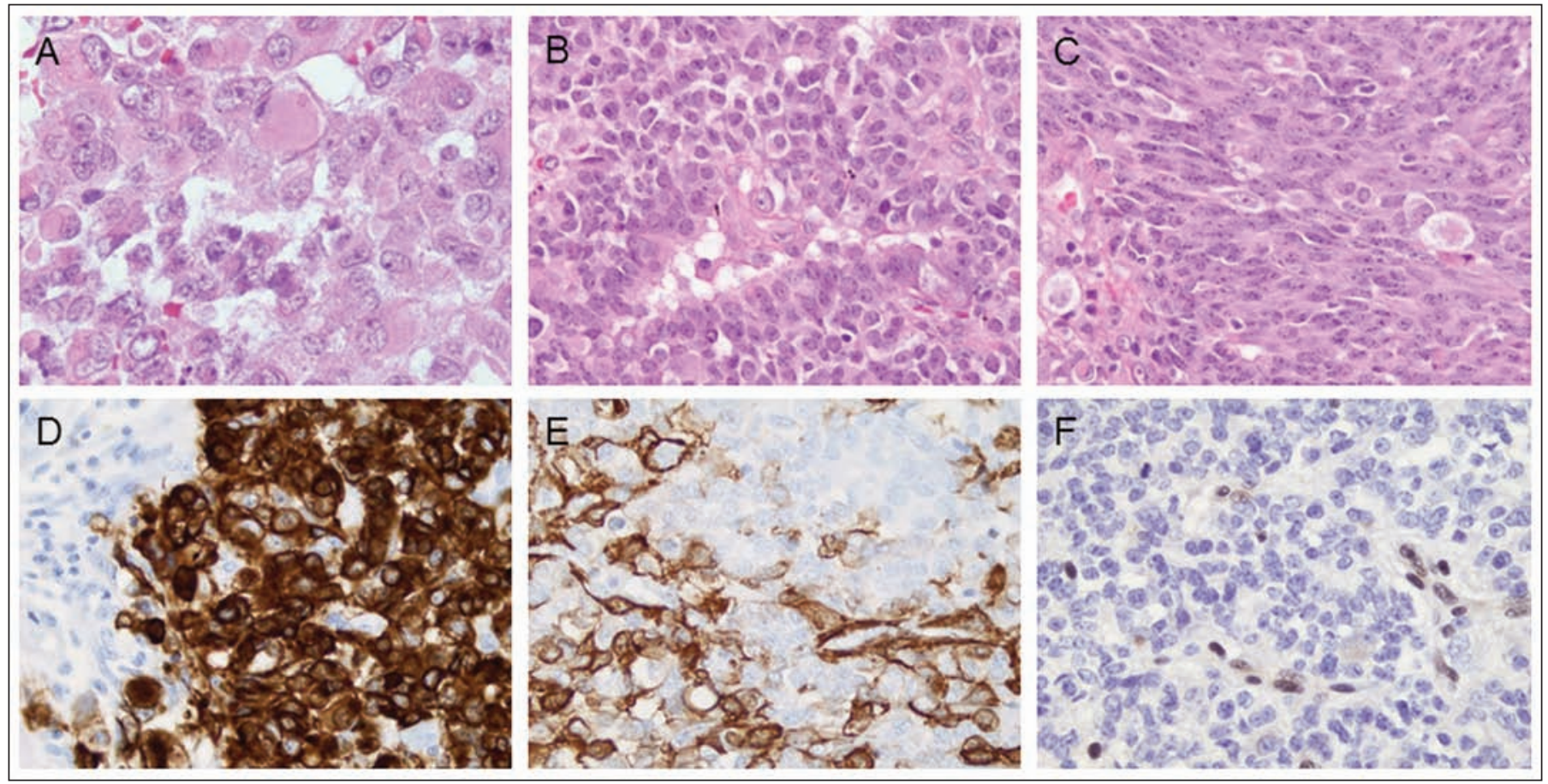

Figure 2: Representative pathological features of an atypical teratoid/rhabdoid tumor (Case 1, in the Table). The tumor shows (A) scattered rhabdoid cells with eosinophilic globular cytoplasmic inclusions, (B) focal epithelioid differentiation, (C) focal mesenchymal differentiation, patchy immunoreactivity for $(D)$ CAM5.2 and $(E)$ smooth muscle actin, and $(F)$ loss of the immunoreactivity for IHI-1 in tumor cells (with its preservation in the blood vessel cells). Original magnifications: $x 630$ (A); x $400(B-F)$. 

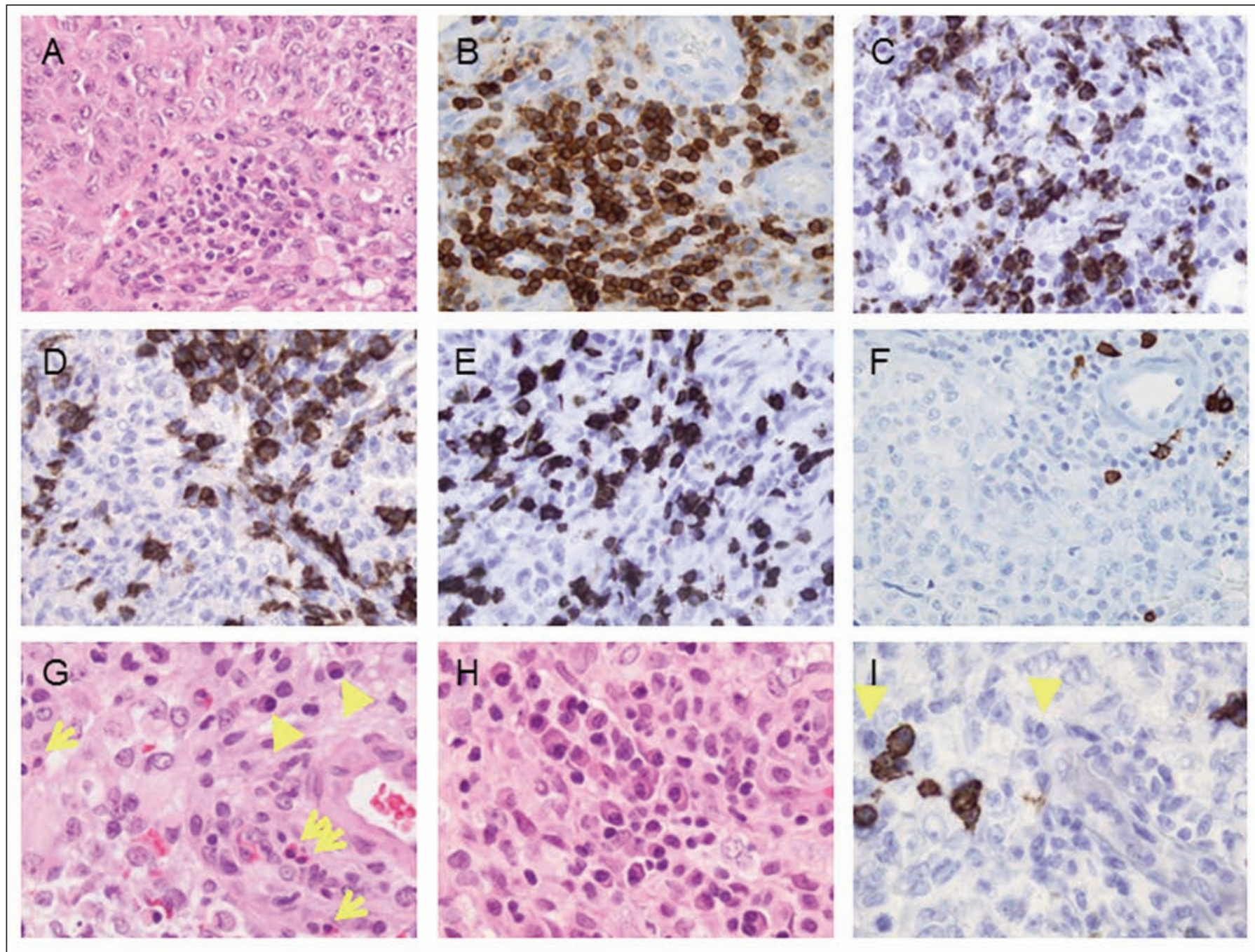

Figure 3: Infiltration of immune/inflammatory cells in an atypical teratoid/rhabdoid tumor (Case 2, in the Table). The tumor exhibits (A) moderate infiltration of immune/inflammatory cells which are $(B)$ immunoreactive for CD45 and contain $(C)$ focally frequent CD68+ macrophages/microglia, $(D)$ $C D 4+$ cells and $(E) C D 8+T$-cells, but $(F)$ sparse CD2O+B-cells. $(G$, arrows) Eosinophils and (G, arrowheads) plasmacytoid cells are often seen. The plasmacytoid cells are $(H)$ focally frequent, and (I, arrowheads) mostly negative for the plasma cell marker CD138. Original magnifications: $x 400$ (A-I).

\section{Infiltration of immune cells}

All AT/RTs contained moderate infiltration of immune or chronic inflammatory cells (Figure 3 and Figure 4A-D) that were labelled by CD45 (Figure 3B). The infiltration of these cells was widespread and preferentially, but not exclusively, surrounding blood vessels. The infiltrating cells were predominantly macrophages/microglia and lymphocytes by morphology. CD68+ macrophages/microglia were scattered to focally abundant (Figure 3C and 4B), so were CD4+ cells (Figure 3D and $4 C$ ). CD8+ T-cells were scattered to focally frequent (Figure $3 \mathrm{E}$ and $4 \mathrm{D}$ ). CD20+ B-cells were sparse (overall less than $1 \%$ of total cells; Figure 3F). Variable numbers of eosinophils and plasmacytoid cells were identified in all four cases (Figure 3G and Figure 4A). The plasmacytoid cells were focally frequent (Figure 3H), and mostly negative for CD138 (Figure 3I, arrowheads); CD138+ plasma cells were only occasionally seen
(Figure 3I). Neutrophils were hardly found in the non-necrotic areas.

In comparison, glioblastomas also showed moderate infiltration of immune or chronic inflammatory cells (Figure 4EH) predominantly comprising CD68+ macrophages/ microglia (Figure 4F) and CD4+ cells (Figure 4G). There was no significant difference in the scores of CD68+ macrophages/ microglia ( $\mathrm{p}=0.11$ by Mann-Whitney test $)$ and CD4+ cells $(\mathrm{p}=$ 0.69 by Mann-Whitney test) between AT/RTs (Figure 4B and 4C, respectively) and glioblastomas (Figure $4 \mathrm{~F}$ and $4 \mathrm{G}$, respectively). In these glioblastomas, however, CD8+ T-cells were occasionally seen (Figure 4H). The scores of CD8+ T-cells were significantly higher in AR/RTs (Figure 4D) than those in glioblastomas ( $p=0.03$ by Mann-Whitney test). Furthermore, the ratio of $\mathrm{CD} 4+/ \mathrm{CD} 8+$ cells was significantly lower in AT/RTs than in glioblastomas ( $p=0.03$ by Mann-Whitney test). Similar 

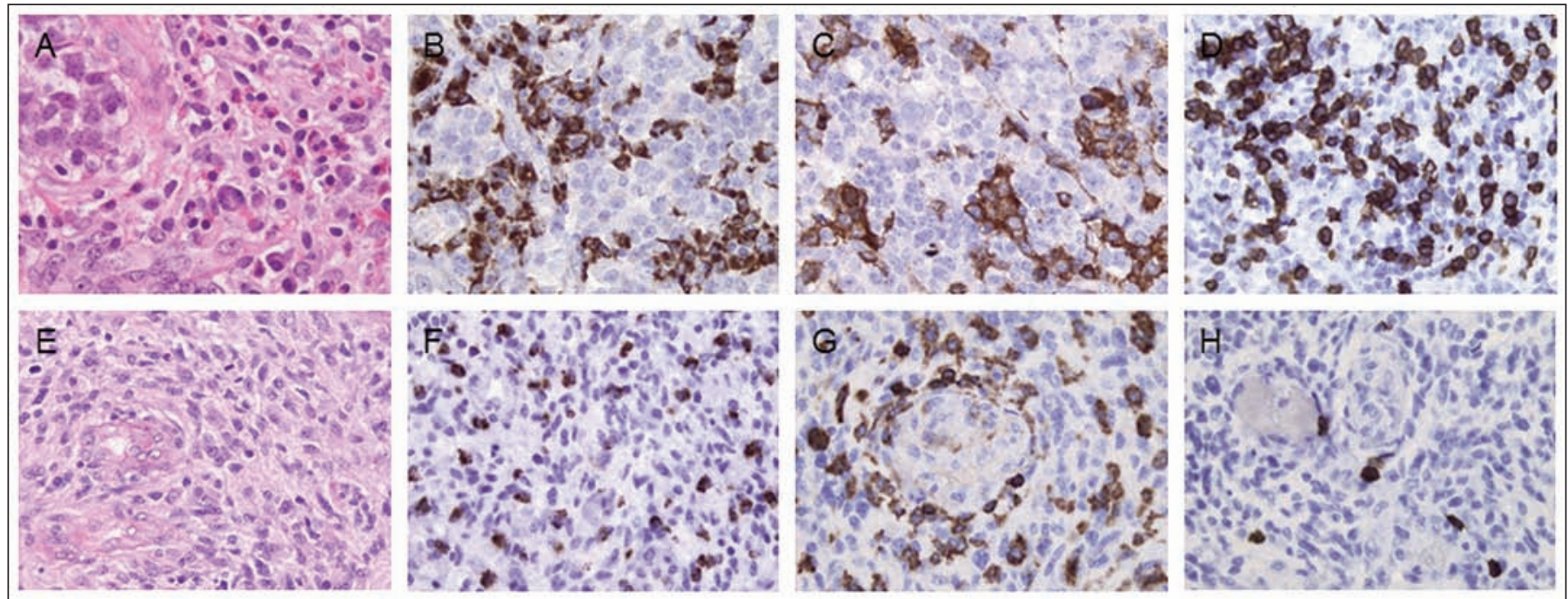

Figure 4: Comparison in the infiltration of immune/inflammatory cells between an atypical teratoid/rhabdoid tumor (AT/RT) Case 1, in the Table) and a glioblastoma (Case 5, in the Table). Compared to the AT/RT which contains abundant immune/inflammatory cells including (A) scattered eosinophils and plasmacytoid cells, (B) focally frequent CD68+ macrophages/microglia, (C) CD4+ cells, and (D) CD8+ T-cells, (E) the glioblastoma showed similar infiltration of $(F) C D 68+$ macrophages/microglia and $(G) C D 4+$ cells, but $(H)$ much less infiltration of CD8+T-cells and $(E)$ absence of eosinophils and plasmacytoid cells. Original magnifications: $x 400(A-H)$.

to AT/RTs, the glioblastomas contained sparse CD20+ cells. Unlike AT/RTs, these glioblastomas were devoid of eosinophils and plasmacytoid cells.

\section{DiscusSION}

The present study has demonstrated a case of AT/RT associated with the autoimmune disease HSP; we have subsequently found that this and other AT/RTs patients have a significantly higher infiltration of CD8+ T-cells, and thus lower ratio of $\mathrm{CD} 4+/ \mathrm{CD} 8+$ cells, compared with those in glioblastomas. We have also discovered the presence of eosinophils in AT/RTs but not in glioblastomas. These findings are novel and suggest an immune microenvironment for the development and progression of AT/RTs.

The CNS has historically been considered an immuneprivileged organ where immune activity is significantly silenced $^{7,23}$. When CNS injury occurs, resident antigenpresenting cells of the CNS, microglia cells, undergo activation and upregulate both the major histocompatibility complex (MHC) and costimulatory molecules, and also contribute to the responses of $\mathrm{CD} 4+$ and $\mathrm{CD} 8+$ specific $\mathrm{T}-\mathrm{cell}_{\mathrm{s}}{ }^{23-25}$. The infiltration of these immune cells has been well demonstrated in glioblastomas ${ }^{8-12}$, which is in agreement with our findings in glioblastomas. Although the histogenesis of AT/RTs remains unknown, AT/RTs and glioblastomas share some components and features such as GFAP-immunoreactive glial component and CD133-immunoreactive CSCs, as well as the common features of CNS malignant tumors including necrosis and high proliferation $^{22}$. The overlap in histopathology and immunohistochemistry between these two malignant CNS tumors is in accord with our findings of the lack of difference in the infiltration of CD68+ macrophages/microglia and CD4+ cells. The reasons for using the standard (adult) glioblastomas as controls in our study are that adult glioblastomas are well described to have significant infiltration of immune cells, while pediatric glioblastomas (despite their age-matching with AT/RTs) are infrequently studied and somewhat dis-similar to their adult counterparts in histopathology and molecular genetic profile ${ }^{26}$. Although the literature is more extensive with respect to adult glioblastoma inflammatory infiltrates, pediatric glioblastomas represent an important additional group in future studies.

We did find a few differences in the infiltration of immune cells between AT/RTs and glioblastomas. Our major finding is that, compared with glioblastomas, AT/RTs show a greater infiltration of CD8+ T-cells. This finding of lower CD8+ T-cell infiltration in glioblastomas is compatible with a recently published study ${ }^{12}$, although we did not examine perivascular Virchow-Robin spaces (partially due to their absence in most of our AT/RT cases). Growing evidence has suggested that CD8+ Tcells contribute significantly to autoimmune response in the $\mathrm{CNS}^{27}$. CD8+ T-cells are diverse in functions. With their cytotoxic properties, CD8+ may initially infiltrate into tumors and attempt to eradicate tumor cells, but they may also have regulatory functions and initiate an autoimmune response possibly against tumor-associated antigens ${ }^{27,28}$. The altered ratio of CD4+ to CD8+ cells in AT/RTs is further in favour of an autoimmune response.

The infiltration of eosinophils seems to be universal in AT/RTs, but absent in glioblastomas. Although Case 1 AT/RT in this study may be expected to have the eosinophilic infiltrates because of associated $\mathrm{HSP}^{29}$, the finding of eosinophils in other AT/RT cases suggests that eosinophils play a role in response to AT/RT growth. Eosinophils are released from the bone marrow and recruited in response to tissue inflammation. They serve as a source of pro-inflammatory mediators including granule- 
stored cationic proteins, cytokines, chemokines, and oxygen burst components, which mediate immune responses ${ }^{30-32}$. Once the eosinophils have selectively infiltrated into inflamed tissues, however, they become activated and release various toxic, harmful proteins including major basic protein, eosinophil cationic protein, eosinophil peroxidase, and eosinophil neurotoxin, which contribute to tissue damage ${ }^{29,32}$. The role of eosinophils in AT/RTs deserves further investigation, which may be dual as eosinophils can induce neurotoxicity to the adjacent brain tissue and/or apoptosis of tumor cells.

Although the present study shows no significant difference in the total number of CD4+ cells between AT/RTs and glioblastomas, the proportion of subclasses of CD4+ cells infiltrating into AT/RTs appears different. CD4+ cells consist at least of helper T-cells and plasmacytoid dendritic cells ${ }^{33,34}$. Plasmacytoid cells identified by morphology in the present study are much more prominent in AT/RTs than in glioblastomas. Given their immunohistochemical profile (negative for the markers of plasma cells and B-cells), most of them represent plasmacytoid dendritic cells in the present study. Plasmacytoid dendritic cells have multiple immunostimulatory functions particularly of producing type I interferons which promote NK and CD8+ T-cell cytotoxicity. They can induce expansion of antigen-specific memory CD8+ T-cells and helper T-cells specific for endogenous antigens ${ }^{35}$. Therefore, the higher infiltration of plasmacytoid cells in AT/RTs may correspond with the higher number of CD8+ T-cells.

It has been accepted that tumor cells express unique antigens which trigger immune responses and serve as targets for antitumor immunity ${ }^{36-39}$. Genetic instability within malignant cells gives rise to aberrant proteins, such as the products of mutated or rearranged oncogenes, tumor suppressor genes, tumor differentiation genes or embryonic antigens. These aberrant proteins have the potential to be recognized as antigens by the host immune system ${ }^{37,38}$. The immune response against tumor-associated antigens has been suggested to be mediated by synergistic CD4+ and CD8+ T-cells within the CNS. A hypothesis for this autoimmune process is that after CD8+ Tcell-mediated lysis of tumor cells, inflammatory antigenpresenting cells, including macrophages and dendritic cells, phagocytize the tumor debris and subsequently present processed tumor antigens to CD4+ and CD8+ T-cells ${ }^{36,39}$. In AT/RTs, raised infiltration of CD8+ T-cells and other immune cells in AT/RTs may possibly be in response to some antigens specifically of mutated genes (for example INI-1 gene) and/or embryonic antigens. There are also other possibilities such as a pseudotumor (exogenous; for example, viral infection) antigen responsible for the antigen-specific immune response in AT/RTs ${ }^{27,39}$.

A limitation of our histopathological study is the inability to confirm causation. The exact mechanisms of these immune cell infiltrates and prognostic significance in AT/RTs require further studies. In our present study, three patients with AT/RT died between 4 and 13 months after their surgical resection; as described earlier, the AT/RT patient with associated HSP has been free of tumor recurrence postoperatively for at least 12 months.

\section{CONCLuSION}

Our findings of the immune cell infiltrates in AR/RTs have provided new insights into the immune microenvironment of this highly malignant brain tumor. A better understanding of this microenvironment that is conducive for the tumor development and progression is crucial for developing more specific treatments of AT/RTs. In malignant gliomas, the immunotherapies using antibodies (passive immunotherapy) and developing vaccines (active immunotherapy) against brain CSCs have been promising ${ }^{6}$. Compared with malignant gliomas, AT/RTs have the similar impaired cell-mediated immunity and even more immune effectors particularly of CD8+ T-cells and eosinophils. Our present study suggests the potential use of immunotherapy also in treating AT/RTs.

\section{ACKNOWLEDGEMENTS}

The authors thank Dr. Lothar Resch for sharing his cases with us and critical reading of the manuscript. This study is supported in part by Canadian Institutes of Health Research (VWY).

\section{REFERENCES}

1. Rorke LB, Packer RJ, Biegel JA. Central nervous system atypical teratoid/rhabdoid tumors of infancy and childhood: definition of an entity. J Neurosurg. 1996; 85:56-65.

2. Chi SN, Zimmerman MA, Yao X, et al. Intensive multimodality treatment for children with newly diagnosed CNS atypical teratoid rhabdoid tumor. J Clin Oncol. 2009;27:385-9.

3. Finkelstein-Shechter T, Gassas A, Mabbott D, et al. Atypical teratoid or rhabdoid tumors: improved outcome with high-dose chemotherapy. J Pediatr Hematol Oncol. 2010;32:e182-6.

4. Nicolaides T, Tihan T, Horn B, Biegel J, Prados M, Banerjee A. High-dose chemotherapy and autologous stem cell rescue for atypical teratoid/rhabdoid tumor of the central nervous system. J Neurooncol. 2010;98:117-23.

5. Chiou SH, Kao CL, Chen YW, et al. Identification of CD133positive radioresistant cells in atypical teratoid/rhabdoid tumor. PLoS One. 2008;3:e2090.

6. Ji J, Black KL, Yu JS. Glioma stem cell research for the development of immunotherapy. Neurosurg Clin N Am. 2010; 21:159-66.

7. Han SJ, Kaur G, Yang I, Lim M. Biologic principles of immunotherapy for malignant gliomas. Neurosurg Clin N Am. 2010;21:1-16.

8. Wu A, Wei J, Kong LY, et al. Glioma cancer stem cells induce immunosuppressive macrophages/microglia. Neuro Oncol. 2010;12:1113-25.

9. Yang I, Han SJ, Kaur G, Crane C, Parsa AT. The role of microglia in central nervous system immunity and glioma immunology. $\mathrm{J}$ Clin Neurosci. 2010;17:6-10.

10. Bingle L, Brown NJ, Lewis CE. The role of tumour-associated macrophages in tumour progression: implications for new anticancer therapies. J Pathol. 2002;196:254-65.

11. Hussain SF, Yang D, Suki D, Aldape K, Grimm E, Heimberger AB. The role of human glioma-infiltrating microglia/macrophages in mediating antitumor immune responses. Neuro Oncol. 2006;8: 261-79.

12. Yang I, Han SJ, Sughrue ME, Tihan T, Parsa AT. Immune cell infiltrate differences in pilocytic astrocytoma and glioblastoma: evidence of distinct immunological microenvironments that reflect tumor biology. J Neurosurg. 2011;115:505-11.

13. Roszman TL, Brooks WH, Steele C, Elliott LH. Pokeweed mitogen-induced immunoglobulin secretion by peripheral blood lymphocytes from patients with primary intracranial tumors. Characterization of $\mathrm{T}$ helper and $\mathrm{B}$ cell function. J Immunol. 1985; $134: 1545-50$ 
14. Brooks WH, Markesbery WR, Gupta GD, Roszman TL. Relationship of lymphocyte invasion and survival of brain tumor patients. Ann Neurol. 1978;4:219-24.

15. Dunn GP, Dunn IF, Curry WT. Focus on TILs: Prognostic significance of tumor infiltrating lymphocytes in human glioma. Cancer Immun. 2007;7:12.

16. Fadul CE, Fisher JL, Gui J, Hampton TH, Côté AL, Ernstoff MS. Immune modulation effects of concomitant temozolomide and radiation therapy on peripheral blood mononuclear cells in patients with glioblastoma multiforme. Neuro Oncol. 2011;13: 393-400.

17. González LM, Janniger CK, Schwartz RA. Pediatric HenochSchönlein purpura. Int J Dermatol. 2009;48:1157-65.

18. Ozkaya O, Bek K, Alaca N, Ceyhan M, Açikgöz Y, Taşdemir HA. Cerebral vasculitis in a child with Henoch-Schönlein purpura and familial Mediterranean fever. Clin Rheumatol. 2007;26: 1729-32.

19. Saulsbury FT. Henoch-Schönlein purpura. Curr Opin Rheumatol. 2010;22:598-602.

20. Fathallah-Shaykh HM, Gao W, Cho M, Herrera MA. Priming in the brain, an immunologically privileged organ, elicits anti-tumor immunity. Int J Cancer. 1998;75:266-76.

21. Holladay FP, Choudhuri R, Heitz T, Wood GW. Generation of cytotoxic immune responses during the progression of a rat glioma. J Neurosurg. 1994;80:90-6.

22. Louis DN, Ohgaki H, Weistler OD, Cavenee WK. WHO Classification of Tumors of the Central Nervous System, ed 4. Lyon: IARC press; 2007.

23. Couraud PO. Interactions between lymphocytes, macrophages, and central nervous system cells. J Leukoc Biol. 1994;56:407-15.

24. Aloisi F, Ria F, Columba-Cabezas S, Hess H, Penna G, Adorini L. Relative efficiency of microglia, astrocytes, dendritic cells and $\mathrm{B}$ cells in naive CD4+ $\mathrm{T}$ cell priming and Th1/Th2 cell restimulation. Eur J Immunol. 1999;29:2705-14.

25. Aloisi F, Ria F, Penna G, Adorini L. Microglia are more efficient than astrocytes in antigen processing and in Th1 but not Th2 cell activation. J Immunol. 1998;160:4671-80.

26. Suri V, Das P, Pathak P, et al. Pediatric glioblastomas: a histopathological and molecular genetic study. Neuro Oncol. 2009;11:274-80
27. Deckert M, Sanchez-Ruiz M, Brunn A, Schluter D. Role of CD8 Tcell-mediated autoimmune diseases of the central nervous system. Crit Rev Immunol. 2010;30:311-26.

28. Watanabe MA, Oda JM, Amarante MK, Cesar Voltarelli J. Regulatory $\mathrm{T}$ cells and breast cancer: implications for immunopathogenesis. Cancer Metastasis Rev. 2010;29:569-79.

29. Tahan F, Dursun I, Poyrazoglu H, Gurgoze M, Dusunsel R. The role of chemokines in Henoch Schonlein Purpura. Rheumatol Int. 2007:27:955-60.

30. Correale J, Fiol M. Activation of humoral immunity and eosinophils in neuromyelitis optica. Neurology. 2004;63: 2363-70.

31. Gleich GJ. Mechanism of eosinophil-associated inflammation. J Allergy Clin Immunol. 2000;105:651-63.

32. Navarro S, Boix E, Cuchillo CM, Nogués MV. Eosinophil-induced neurotoxicity: the role of eosinophil cationic protein/RNase 3. J Neuroimmunol. 2010;227:60-70.

33. Colonna M, Trinchieri G, Liu YJ. Plasmacytoid dendritic cells in immunity. Nat Immunol. 2004;5:1219-26.

34. Murphy KM, Reiner SL. The lineage decisions of helper T cells. Nat Rev Immunol 2002;2:933-44.

35. Krug A, Veeraswamy R, Pekosz A, et al. Interferon-producing cells fail to induce proliferation of naive $\mathrm{T}$ cells but can promote expansion and $\mathrm{T}$ helper 1 differentiation of antigen-experienced unpolarized T cells. J Exp Med. 2003;197:899-906.

36. Boon T, Cerottini JC, Van den Eynde B, van der Bruggen P, Van Pel A. Tumor antigens recognized by $\mathrm{T}$ lymphocytes. Annu Rev Immunol. 1994;12:337-65.

37. Kurpad SN, Zhao XG, Wikstrand CJ, Batra SK, McLendon RE, Bigner DD. Tumor antigens in astrocytic gliomas. Glia. 1995; $15: 244-56$.

38. Shu S, Plautz GE, Krauss JC, Chang AE. Tumor immunology. JAMA. 1997;278:1972-81.

39. Liau LM, Jensen ER, Kremen TJ, et al. Tumor immunity within the central nervous system stimulated by recombinant Listeria monocytogenes vaccination. Cancer Res. 2002; 62: 2287-93. 